\title{
Review of "Open Access"
}

Innocent Awasom

1 Texas Tech University

QED 